\title{
LATRAGEDIA DE JULIO CÉSAR DE WILLIAM SHAKESPEARE: VIOLENCIA Y RETÓRICA EN LA ANTIGUA ROMA
}

\author{
The tragedy of Julius Caesar by William Shakespeare: violence and rhetoric in \\ Ancient Rome
}

\author{
María Angelina Cazorla* \\ Universidad Nacional del Nordeste \\ angelinacazorla@hotmail.com
}

Palabras clave

Roma;

Julio César;

William Shakespeare;

tragedia;

violencia;

retórica

\section{Keywords}

Rome;

Julius Caesar;

William Shakespeare;

tragedy;

violence;

rhetoric

\section{Resumen}

De las treinta y siete obras atribuidas al autor inglés William Shakespeare, seis de ellas tratan sobre temas relacionados con la antigua Roma. En esta oportunidad nos ocuparemos de La tragedia de Julio César que escenifica la muerte del líder romano (44 a.C.) a manos de Bruto y Casio. El propósito del presente trabajo será, pues, revelar el modelo romano shakespeareano escenificado durante la época premoderna. El análisis de la obra incluirá breves comentarios histórico-revisionistas de la Inglaterra isabelino-jacobina; y se abordará desde el andamiaje idiosincrático del drama histórico romano de Shakespeare, según los postulados de Robert Miola (2002, 2004). En varios trabajos dedicados al estudio de la antigua Roma representada en los escenarios renacentistas, el profesor Miola pone de manifiesto las tensiones de una antigüedad clásica caracterizada, en la modernidad temprana, por lo distinto o diferente (violencia) y la identidad o similitud (retórica) en relación con la construcción histórica, ideal y estereotipada de ese pasado.

\begin{abstract}
Of the thirty-seven works attributed to the English author William Shakespeare, six of them deal with themes related to ancient Rome. We will study The Tragedy of Julius Caesar, which represents the death of the Roman leader (44 BC) at the hands of Brutus and Cassius. The purpose of this paper will beto reveal the Shakespearean Roman model staged during the pre-modern era. The drama analysis will includebrief historical-revisionist comments on Elizabethan-Jacobean England; and we will approach the text from Robert Miola's ideas on Shakespeare's Roman historical drama. In several works devoted to the study of ancient Rome, as seen during the Renaissance, Professor Miola reveals the tensions of classical ancient Rome characterized, in early modern time, by violence and rhetoric in relation to the historical, ideal and stereotyped construction of the past.
\end{abstract}




\section{La tragedia de Julio César de William Shakespeare: violencia y retórica en la antigua Roma}

\section{Introducción}

La civilización grecolatina es considerada el pilar fundacional de la cultura y el saber occidental. La arquitectura, la religión, la lengua y la escritura de Inglaterra, como las del resto de Europa continental, tienen íntima relación con el gran Estado Romano. Para un mejor testimonio de la influencia romana en la evolución cultural de este archipiélago, nada más acertado que las palabras de Chesterton: "cuando se estudia la primera mitad de la historia inglesa, la Roma pre-cristiana está presente” (2013, p. 14). Cayo Julio César, procónsul de Galia, cruzó dos veces la estrecha franja de agua $^{1}$ que separa las islas británicas del continente. La primera incursión, en el año 55 a.C., no fue ni permanente ni exitosa; pero la segunda, al año siguiente, fue más prolongada y organizada. Un siglo después (año 43 d.C.) de que aquellas primeras legiones desembarcaran en la costa de Kent (extremo sudoccidental de la isla), Britania ${ }^{2}$ se convirtió en "una de las cuarenta y cinco provincias del Imperio Romano" (Churchill, 1958, p. 50). De hecho, la más distante y septentrional de Roma. En el año 410 d.C. ${ }^{3}$ comienza el colapso del dominio directo del Imperio en las provincias occidentales, incluida la Britannia Romana. Hoy en día, todavía se conserva una capa del barniz de la romanización (que no alcanzó a cubrir completamente ${ }^{4}$ todos los aspectos): las murallas de Adriano y Antonio, los anfiteatros extramuros, los caminos rectilíneos, los hipocaustos, ${ }^{5}$ los baños termales públicos, las cloacas y las villas, entre otras obras de ingeniería (Tomlin, 2018, p. 83-125).

El florecimiento de Roma en Britania también se encuentra cuidadosamente conservado en las esferas del arte literario. Al imaginar la ciudad latina en sus obras, el autor inglés William Shakespeare recupera la antigüedad clásica que el renacimiento isabelino promovía en los siglos XVI y XVII (Miola, 2004, p. 3). De las treinta y siete obras atribuidas al bardo de Stratford, seis de ellas se ocupan de temas surgidos de la antigua Roma. Ellas son: La violación de Lucrecia, Coriolano, Julio César, Antonio y Cleopatra, Tito Andrónico y Cimbelino. Sin embargo, la más destacada es la dedicada al asesinato del general romano (44 a. C.), hecho sobre el cual se ha detenido la mirada de la historia y la literatura. La tragedia de Julio César, drama que se representa entre los años 1599-1601, escenifica la muerte del líder político a manos de varios conspiradores liderados por Bruto y Casio en defensa de la libertad republicana. En esta breve obra pre-moderna nos encontramos con una Roma que se esfuerza por acomodar al César como autoridad suprema de una monarquía artificial, durante la gestación de una nueva estructura política.

1. En la actualidad, es el Paso de Calais que, en su parte más angosta, solo tiene $35 \mathrm{~km}$.

2. Nombre de las tierras habitadas por los celtas en tiempos romanos.

3. Año en que Alarico saqueó Roma (Townson, 2015, p. 32).

4. La romanización se produjo entre las clases superiores y concentradas en las grandes ciudades como York, Chester $y$ Londinum.

5. Horno subterráneo que calentaba los baños y suministraba agua caliente a las termas. 
Fue en la escuela de gramática local donde William Shakespeare aprendió las inflexiones, la morfología, la sintaxis, las figuras retóricas y la prosodia de la gramática latina. La expresión que balbuceó César moribundo: "Et tu, Brute?" (III, 1 p. 40) deriva de aquellos rudimentos latinos aprendidos en los primeros años de escolarización del poeta, aspecto al que Peter Ackroyd dedica un número considerable de páginas en su biografía (2005, p. 5-32). La investigación sobre Julio César requería, asimismo, de lecturas suplementarias provenientes de fuentes primarias, como The Lives of the Noble Grecians and Romanes, de Plutarco (1579) en la traducción de Sir Thomas North (en Hutchins, 1952). En ella, el historiador griego presenta a un César en decadencia, con poco de instinto soberano todavía. En este sentido, Shakespeare decidió que su obra requería, también, de un César arrogante, vanidoso, terco y declinante; pero con una mezcla plausible de grandezas supremas y debilidades humanas (de Grazia, 2001, p. 31-48).

Shakespeare imagina a Roma -modelo de la oratoria y la retórica occidentales- como una ciudad brutal, violenta, extraña y distante (Miola, 2002, p. 194). El propósito del presente trabajo será, pues, revelar el modelo romano shakespeariano escenificado durante la época premoderna. En este modelo, el autor se toma algunas licencias dramáticas con el fin de que la audiencia isabelina encuentre referencias históricas locales en su Roma de ficción. El análisis de la obra incluirá breves comentarios histórico-revisionistas de la Inglaterra isabelino-jacobina; y se lo abordará desde el andamiaje idiosincrático del drama histórico romano de Shakespeare, según los postulados de Robert Miola (2002, 2004). En dos capítulos dedicados al estudio de la Antigua Roma ${ }^{6}$ representada en los escenarios renacentistas, el profesor Miola pone de manifiesto las tensiones de una antigüedad clásica caracterizada, en la modernidad temprana, por lo distinto o diferente (violencia) y la identidad o similitud (retórica) en relación con la construcción histórica, ideal y estereotipada de ese pasado.

\section{Diferencias en la espectacularidad, la escenificación y la teatralidad de la violencia}

La historia de la antigua Roma que el renacimiento europeo y la Inglaterra isabelina intentaron rescatar es, asimismo, una historia de crueldad, ambición y degradación moral. Roma forjó un imperio fundado sobre el fratricidio, la guerra y la conquista. Es, en este sentido, que la espectacularidad de la violencia se aprecia en todos los trabajos de William Shakespeare que tratan sobre temas romanos: violación, venganza, suicidio, mutilación, desmembramiento, canibalismo, conspiración, asesinatos y ejecuciones. Según Miola, Shakespeare inventa un exagerado ritual de sangre que, en ocasiones, decide solo verbalizar y no representar sobre el proscenio con el fin de que la audiencia isabelina encontrara menos cruenta la escenificación.

El patriotismo de Bruto, a quien al finalizar la obra se lo llama elogiosamente "el más noble romano de todos ellos" (V,2, p. 100) -distinguiéndolo de este modo del resto de los conspiradores- lo mueve a traicionar y apuñalar a Julio César para salvar a Roma del cesarismo: teme que César, una vez coronado, se convierta en otro Tarquino. ${ }^{7}$

6. Ver Shakespearés Ancient Rome: difference and identity (Miola, 2002, p. 193-213) y Julius Caesar: Rome divided (Miola, 2004, p. 76-115).

7. Recordemos que Bruto tiene el linaje de aquellos antecesores que expulsaron a los reyes Tarquinos de Roma. 
Para William Shakespeare, Bruto es solo el dirigente de una conspiración cuyos planes efectivos culminan con la matanza de César. Su vocerío ante la muchedumbre expectante: “¡Libertad, liberación y emancipación!" (III, 1, p. 49) y su ineptitud parlamentaria para realizar una oración fúnebre (pues se expresa de manera simple, breve y en prosa) $)^{8}$ son "paradójicamente hipócritas en relación a los austeros valores y las virtudes de romanitas y pietas" (Miola, 2002, p. 194). La muchedumbre despavorida ante el asesinato espera una explicación, una justificación o una eximición de su conducta:

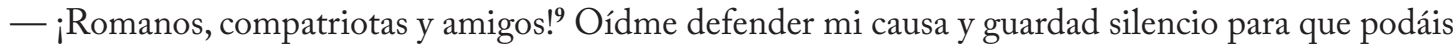
oírme. Creedme por mi honor y respetad mi honra, a fin de que me creáis. Juzgadme con vuestra rectitud y avivad vuestros sentidos para poder juzgar mejor. Si hubiese alguno en esta asamblea que profesara entrañable amistad a César, a él le digo que el afecto de Bruto por César no era menos que el suyo. Y si entonces ese amigo preguntase por qué Bruto se alzó contra César, ésta es mi contestación: 'No porque amaba a César menos, sino porque amaba más a Roma.' ¿Preferiríais que César viviera y morir todos esclavos a que esté muerto César y todos vivir libres? Porque César me apreciaba, le lloro; porque fue afortunado, le celebro; como valiente, le honro; pero por ambicioso, le maté. Lágrimas hay para su afecto, gozo para su fortuna, honra para su valor y muerte para su ambición. ¿Quién hay aquí tan abyecto que quisiera ser esclavo? ¡Si hay alguno, que hable, pues a él he ofendido! ¿Quién hay aqui tan estúpido que no quisiera ser romano? ¡Si hay alguno, que hable, pues a él he ofendido! ¿Quién hay aquí tan vil que no ame a su patria? ¡Si hay alguno, que hable, pues a él he ofendido! (...)

- ¡Entonces, a nadie he ofendido! ¡No he hecho con César sino lo que haríais con Bruto! Los motivos de su muerte están escritos en el Capitolio. Su gloria no se amengua, en cuanto la merecía, ni se exageran sus ofensas, por las cuales ha sufrido la muerte.

(Entran ANTONIO y otros con el cuerpo de CÉSAR.)

Aquí llega su cuerpo, que doliente conduce Marco Antonio, que, aunque no tomó parte en su muerte, percibirá los beneficios de ella, o sea un puesto en la república. ¿Quién de vosotros no obtendrá otro tanto? Con esto me despido, que, igual que he muerto a mi mejor amigo por la salvación de Roma, tengo el mismo puñal para mí propio cuando plazca a mi patria necesitar mi muerte. (III, 1, p. 54-55)

Según lo pactado entre los conspiradores en el Capitolio, Bruto debe ser el primer orador. Comienza su discurso con una exclamación apelativa para captar la atención del público con las palabras: “¡Romanos, compatriotas y amigos!”. Marco Antonio usará la misma captatio benevolentiae con diferentes palabras. Seguidamente, somos testigos de un discurso que intenta explicar un acto preventivo: César aún no había hecho nada malo, pero debía eliminarlo para evitar el posible o probable desenlace (la esclavitud) resultante de la ambición desmedida de César. En este alegato se refiere a sí mismo en tercera persona -según se observa en las expresiones destacadas en cursiva-. Esta figura estilística de auto-referencia le confiere, al diciente, una supremacía y predominio que todo el auditorio debe reconocer (Miola, 2002, p. 203). Su exordio plantea una estrategia racionalmente argumentativa que busca manipular y persuadir a los plebeyos en el Foro. Si bien reconoce el amor de César, Bruto debe defender su causa republicana, justificar el asesinato y legitimar el magnicidio. Deja muy en claro que ejecuta a un amigo para eliminar a un tirano; es decir, antepone el bienestar colectivo a la indignidad de matar a un ser querido, cuyo único vicio era la ambición. Comienza recordando a la gente que es un hombre honorable y asume que la multitud establecerá la conexión directa entre

8. En el autor isabelino, la prosa está reservada para las líneas menos serias o auténticas: el parlamento de los bufones, los tontos, los locos o para los estratos inferiores de las clases sociales (Palfrey, 2011, p. 275).

9. Hemos destacado en cursivas algunas expresiones y frases para señalar el poder de las palabras de Bruto y sus estrategias retóricas. 
un hombre de honor y un acto honorablemente motivado. Nótese que Shakespeare le impone ritmo a este discurso mediante el uso del paralelismo, de la antítesis y la repetición de frases u oraciones con la misma estructura gramatical. Este tecnicismo retórico se utiliza para reforzar una idea o concepto, haciéndolo memorable para la audiencia. Al final del parlamento, y a modo de honrar al difunto, da lugar a la loa fúnebre para César que, en una decisión imprudente, le encarga a Marco Antonio.

Siguiendo el razonamiento de Miola, la Roma escénica del Julio César de Shakespeare dista de ser una Roma gloriosa y es, por el contrario, egoísta, contenciosa, cruel y hostil. Momentos después, el auditorio isabelino es testigo de una segunda ejecución en masa sobre el escenario. En una coda casi surrealista, la chusma enfurecida arrastra al inocente poeta Cinna, quien, por tener igual nombre que uno de los conspiradores (Lucio Cornelio Cinna) y estar en el momento y lugar equivocados, es sometido a un juicio simulado por los ciudadanos de Roma. De igual modo, sufre el mismo destino que César al grito de: “-_Desgarradle en pedazos! ¡Es un conspirador!” (III, 3, p. 64). El único rol formal del personaje Cinna, en la estructura interna de la obra, es continuar con la escenificación de la naturaleza predatoria y sanguinaria del pueblo romano e informar al público isabelino que los poetas no prosperan en tiempos de disturbios civiles.

Por otro lado, la autodestrucción en la Roma de Shakespeare emerge como una característica distintiva del pueblo romano pagano. Bruto, Casio, Ticinio y Porcia se suicidan para eludir la ignominia y la humillación pública. La espectacularidad de la mutilación, la escenificación del suicidio y la teatralidad de la muerte definen a la Roma shakespeariana como brutal, violenta, extraña y distante (Miola, 2002, p. 194). Sin embargo, debemos de reconocer que detrás del impulso de representar la violencia romana se esconde, en realidad, el apuro utilitario de establecer paralelos instructivos entre la historia antigua, los conflictos políticos y las tensiones religiosas cercanas al auditorio isabelino. La necesidad de la Inglaterra premoderna no es, por lo tanto, conocer fiel y detalladamente el pasado romano como modelo ejemplar de la civilización occidental, sino interpretarlo como herramienta de disimilitud y semejanza a la luz de su contexto contemporáneo.

Siempre cauto con el poder estatal, el autor presenta a un César tiránico, aunque benigno; un patricio romano como rey predecesor de los gobiernos europeos, mostrando de este modo, y muy sutilmente, su apoyo al régimen monárquico de Isabel I y al absolutismo estricto (y en ocasiones sanguinario) de los Tudor-Estuardo.

\section{La identidad y similitud en la elocuencia, la oratoria y la retórica}

La retórica es el arte o la disciplina que se ocupa del uso del discurso, ya sea oral o escrito, para informar, persuadir, convencer, motivar o influenciar a una audiencia compuesta por una o un grupo de personas (Corbet y Connors, 1999, p. 1). Los retóricos clásicos parecen haber reducido el efecto particular del discurso retórico a la persuasión. Aristóteles define la retórica como la facultad de utilizar todos los medios y las estrategias de persuasión disponibles en cualquier situación. Corbet y Connors (1999, p. 16) afirman que el propósito de Retórica era: 
to convince or persuade and audience to think in certain way or to act in a certain way. Later, the principles of rhetoric were extended to apply to informative or expository modes of discourse, but in the beginning, they were applied almost exclusively to the persuasive modes of discourse. ${ }^{10}$

En comparación con otras obras trágicas de Shakespeare, Julio César (al igual que Coriolano) sigue la preceptiva retórica clásica para construir discursos persuasivos de sus héroes trágicos. En ambas obras, los versos están estrictamente gobernados por el contexto dramático y en consonancia directa con las preocupaciones políticas de la Roma republicana. Como consecuencia, ninguna de las piezas romanas contiene la belleza lírico-poética que sobresale en la mayoría de los restantes trabajos de William Shakespeare (Cantor, 2017, p. 110). Según lo señalábamos más arriba, la escolaridad isabelina abogaba por "un entrenamiento latino muy retórico" (Wills, 2011, p. 39). Se entiende entonces que la retorización clásica, claramente distinguible en los parlamentos de los personajes nobles, siguiera el modelo de los cánones latinos aprendidos por los autores.

Por otro lado, cabe destacar que el soliloquio, recurso dramático fundamental en la tragedia, permite acceder a la conciencia y la psiquis del héroe, que está solo (solus) en el escenario, desaparece o es prácticamente inexistente en el drama histórico (Earley, 1988, p. 10). En este sentido, la elocuencia de Marco Antonio al pronunciar una extensa oratio funebris de 170 líneas es, tal vez, la secuencia más famosa de las obras romanas de Shakespeare; aun cuando se limita a las estrictas condiciones impuestas en el contexto de las exequias. Marco Antonio, quien portará el cadáver, debe conseguir permiso de los asesinos para tener el privilegio de hablar en el Foro. No podrá mencionar la vileza de los conjurados; deberá resaltar, en cambio, las virtudes de César y, además, tendrá que hacerlo desde la misma tarima que Bruto después de que este haya concluido su discurso. Es decir, el pueblo no espera una explicación, una justificación o una excusa lógico-racional (como la de Bruto), sino una prédica emocional.

El mayor triunfo de Julio César es la difusión de su mito, gracias a la elocuencia, la oratoria y la retórica de este segundo orador. Sobre el cadáver ensangrentado, Marco Antonio siembra las bases para el fracaso de la conspiración:

\footnotetext{
— ¡Oh, perdóname, trozo de barro ensangrentado, que aparezca suave y humilde con estos carniceros! ¡Tú representas la ruina del hombre más insigne que viviera jamás en el curso de las épocas! ¡Ay de las manos que vertieron esta preciosa sangre! ¡Ante tus heridas, frescas todavía — cuyas mudas bocas, cuyos rojizos labios se entreabren para invocar de mi lengua la voz y la expresión-, profetizo ahora: caerá una maldición sobre los huesos del hombre: discordias intestinas y los furores de la guerra civil devastarán a Italia entera! ¡Sangre y destrucción serán tan comunes y las escenas de muerte tan familiares que las madres se contentarán con sonreír ante la vista de sus niños descuartizados por las manos de la guerra! ¡Las acciones bárbaras sofocarán toda piedad! ¡Y el espíritu de César, hambriento de venganza, vendrá en compañía de Atis (la diosa de la venganza), salida del infierno, y gritará en

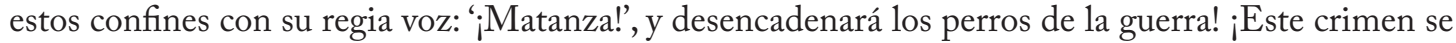
extenderá a todo el universo por los ayes de los moribundos solicitando sepultura! (III, 1, p. 51-52)
}

10. "para convencer o persuadir a la audiencia de que piense de cierta manera o que actúe en cierta forma. Más tarde, los principios de la retórica se ampliaron para aplicarse a modos informativos o expositivos de discurso, pero al principio, eran aplicado casi exclusivamente a los modos persuasivos del discurso" (la traducción es nuestra). 
La retórica de su discurso íntimo toma la forma de una maldición o una profecía, que pronostica más violencia, sangre y matanza en exceso. Las figuras poéticas empleadas por el escritor hacen que este parlamento, a pesar de la violencia que expresa, resulte de una particular belleza.

El cuerpo mutilado de César en su ataúd es visible en el escenario durante la mayor parte de la segunda escena del tercer acto. En el recordatorio del líder, el cadáver cubierto con su capa desgarrada y ensangrentada, la impostación de la voz, los gestos y el movimiento escénico son complementos fundamentales de la representación para lograr el atractivo auditivo del discurso fúnebre en verso blanco:

- AAmigos, romanos, compatriotas, prestadme atención! ;Vengo a inhumar a César, no a ensalzarle! ¡El mal que hacen los hombres les sobrevive! ¡El bien queda frecuentemente sepultado con sus huesos! ¡Sea así con César! El noble Bruto os ha dicho que César era ambicioso. Si lo fue, era la suya una falta, y gravemente lo ha pagado. Con la venia de Bruto y los demás — pues Bruto es un hombre honrado, como son todos ellos, hombres todos honrados - vengo a hablar en el funeral de César. Era mi amigo, para mí leal y sincero, pero Bruto dice que era ambicioso, y Bruto es un hombre honrado. Infinitos cautivos trajo a Roma, cuyos rescates llenaron el tesoro público. ¿Parecía esto ambición en César? Siempre que los pobres dejaran oír su voz lastimera, César lloraba. ¡La ambición debería ser de una sustancia más dura! No obstante, Bruto dice que era ambicioso, y Bruto es un hombre honrado. Todos visteis que en las Lupercales le presenté tres veces una corona real, y la rechazó tres veces. ¿Era esto ambición? No obstante, Bruto dice que era ambicioso, y, ciertamente, es un hombre honrado. ¡No hablo para desaprobar lo que Bruto habló! ¡Pero estoy aquí para decir lo que sé! Todos le amasteis alguna vez, y no sin causa. ¿Qué razón, entonces, os detiene ahora para no llevarle luto? ¡Oh raciocinio! ¡Has ido a buscar asilo en los irracionales, pues los hombres han perdido la razón! ¡Toleradme! ¡Mi corazón está ahí, en ese féretro, con César, y he de detenerme hasta que torne a mí! (...)

-(...) Si estuviera dispuesto a excitar al motín y a la cólera a vuestras mentes y corazones, sería injusto con Bruto y con Casio, quienes, como todos sabéis, son hombres honrados. ¡No quiero ser injusto con ellos! ¡Prefiero serlo con el muerto, conmigo y con vosotros, antes que con esos hombres tan honrados! pero he aqui un pergamino con el sello de César. Lo hallé en su gabinete y es su testamento. ;Oiga el pueblo su voluntad (...)

- (...) al oír el testamento de César os enfureceriais llenos de desesperación. Así, no es bueno haceros saber que os instituye sus herederos. (...)

—TTodos conocéis este manto! (...) ¡Mirad: por aquí penetró el puñal de Casio! ¡Ved qué brecha abrió el implacable Casca! ¡Por esta otra le hirió su muy amado Bruto! ¡Y al retirar su maldecido acero, observad cómo la sangre de César parece haberse lanzado en pos de él, como para asegurarse de si era o no Bruto el que tan inhumanamente abría la puerta! ¡Porque Bruto, como sabéis, era el ángel de César! ¡Juzgad, oh dioses, con qué ternura le amaba César! ¡Ése fue el golpe más cruel de todos, pues cuando el noble César vio que él también le hería, la ingratitud, más potente que los brazos de los traidores, le anonadó completamente! ¡Entonces estalló su poderoso corazón, y, cubriéndose el rostro con el manto, el gran César cayó a los pies de la estatua de Pompeyo, que se inundó de sangre! ¡Oh, qué caída, compatriotas! ¡En aquel momento, yo, y vosotros y todos; caímos, y la traición sangrienta triunfó sobre nosotros! ¡Oh, ahora lloráis y percibo sentir en vosotros la impresión de la piedad! ¡Esas lágrimas son generosas! ¡Almas compasivas! ¿Por qué lloráis, cuando aún no habéis visto más que la desgarrada vestidura de César? ¡Mirad aquí! ¡Aquí está él mismo, acribillado, como veis, por los traidores! (...)

— ¡Buenos amigos, apreciables amigos, no os excite yo con esa repentina explosión de tumulto! Los que han consumado esta acción son hombres dignos. ¿Qué secretos agravios tenían para hacerlo? ¡Ay! Lo ignoro. Ellos son sensatos y honorables, y no dudo que os darán razones. (...) ¡Os muestro las heridas del bondadoso César, pobres, pobres bocas mudas, y les pido que ellas hablen de mí! ¡Pues si yo fuera Bruto y Bruto fuera Antonio, ese Antonio exasperaría vuestras almas y pondría una lengua en cada herida de César, capaz de conmover y levantar en motín las piedras de Roma! (III, 2 p. 56-60) ${ }^{11}$

11. Nuevamente, hemos destacado en cursivas algunas expresiones y frases para señalar la elocuencia, la oratoria y la retórica de Marco Antonio. 
Por los gritos encolerizados que se oyen entre el pueblo expectante, ${ }^{12}$ Marco Antonio entiende que los plebeyos están en su contra. Sin embargo, astutamente comienza la plegaria acortando distancias al llamarlos: "amigos (en primer lugar), romanos y compatriotas; luego les pide, les ruega, les suplica, les ordena: “¡escuchadme!”. Marco Antonio era, en ese momento, el amo de Roma (Asimov, 1966, p. 117); pues no era un hombre de Estado quien pronunciaba el magno discurso, sino un coterráneo que hablaba en tono cordial. El hecho de dirigirse a los ciudadanos en segundo lugar, le permitió escuchar atentamente el discurso de Bruto, quien se justificaba, exculpaba y excusaba con un argumento débil. William Shakespeare sabía muy bien cómo manipular grandes masas y es así como pone en práctica ese magistral ejercicio. Marco Antonio llama irónicamente a Bruto "hombre honrado" en reiteradas ocasiones, convirtiendo a la frase en una antífona hipnótica sin violar ninguno de los preceptos impuestos por los conspiradores. Nuevamente, la figura de la repetición emerge como forma de estructurar la melodía, el metro y el ritmo del verso blanco en el idioma original. La elocuencia y retórica del orador, se ponen otra vez de manifiesto cuando, tras confirmar el carácter ambicioso y avaro de César, Marco Antonio rebate esta afirmación al recordar la triple negativa del dictador ante el ofrecimiento de la corona durante las Lupercales. Seguidamente, sintetiza las grandes hazañas de César; describe las heridas recibidas como recompensa de toda su grandeza, lee su generoso testamento, cuyo beneficiario es el pueblo allí presente, y expresa no solo pena por la pérdida de su amigo, sino ira, odio y un deseo apasionado de venganza. Este ejemplo de magnanimidad, que se mueve entre la curiosidad y la codicia de la audiencia, conmueve profundamente al pueblo, quien clama castigo para los conspiradores. La táctica de Antonio para conmover a la multitud se fundó no solo en su elocuente retórica llena de sentimentalismo, sino y, sobre todo, en el uso de ayudas visuales. Acercándose al cuerpo de César, muestra a la asombrada multitud la túnica desgarrada y ensangrentada del muerto, señalando e identificando cada rasgadura en el manto con el hombre que la hizo; incluso señala la puñalada de Bruto y la describe como "el corte más descortés de todos" (III, 2, p. 61).

\section{Conclusión}

La tragedia de Julio César fue, probablemente, la primera obra que se representó en el teatro The Globe, del cual el dramaturgo era co-propietario. Ese mismo año (1599), los isabelinos enviaron al ejército a aplastar una rebelión irlandesa; resistieron una amenaza naval española y apostaron por una joven Compañía de Indias Orientales. A pesar de lo agitado del panorama interno, había ánimo (y tiempo) para concurrir masivamente a los teatros populares (Shapiro, 2005, p. vii). Para esta misma época, Isabel I, con 65 años, había pasado la edad fértil, no tenía hijos propios ni había nombrado herederos a la corona inglesa, por temor a estimular una conspiración en su contra. Era lógico suponer, pues, que el pueblo inglés manifestara preocupación por las luchas de poder que podrían anteceder a la sucesión monárquica (¿católica?). Ya habían pasado por una situación similar cuando, en 1455, los nobles de dos familias aristocráticas (los York y los Lancaster) descendientes de la misma línea dinástica (los Plantagenet), se enfrentaron en la Guerra de la Rosas, reclamando igual legitimidad para portar la corona. No es un hecho fortuito, entonces, que William Shakespeare recurriera a la

12. Omitidos en este pasaje para evitar la excesiva extensión de la cita. 
antigua Roma y a Julio César como pretextos perfectos para exponer temas sobre la legitimidad del liderazgo. Dejando a un lado las dudas ético-morales que (in)justifican un regicidio (o tiranicidio, según quién argumente), el verdadero problema de un asesinato político es que, invariablemente, precede al derramamiento de sangre, la venganza salvaje y una potencial contienda civil. De eso se trata esta tragedia: de las consecuencias del asesinato de un líder militar perpetrado por un grupo de traidores que cambió el curso de la Roma republicana y su forma de gobierno.

Para William Shakespeare, la única hazaña heroica que realiza Julio César en este drama histórico es morir en los Idus de Marzo. No hay enumeración de hazañas militares, ni de la guerra civil; ni del provocador cruce del río Rubicón, ni mención a la conquista de Galia o Britania; ni se recuerda la alianza temporal con Pompeyo y Craso en el triunvirato; ni se describe su poderoso ejército (Chernaik, 2011, p. 102). Sin embargo, el punto de inflexión es la elegía de Marco Antonio sobre su cadáver (III, 2). El dramaturgo imagina los cambios de tono, las pausas, los silencios, los gestos, los movimientos escénicos, los sangrientos apoyos visuales y la retórica elocuente de un cónsul romano en un discurso más conmovedor que revelador.

William Shakespeare entendía, de igual modo, que lo que los personajes callaban también era importante. A pesar de que César solo articula 155 líneas en cinco escenas, y que el regicidio no está al final sino en el centro exacto de la obra (III, 1), la tragedia lleva el nombre del líder asesinado, ${ }^{13}$ pues "Shakespeare se ve obligado a llamar la obra con su nombre por ser el personaje de más alto rango; como era regla general para el dramaturgo"(Bloom, 2008, p. 152). Aun así, Shakespeare no le adjudica a Julio César ningún soliloquio (Griffin, 2009, p. 382). En La tragedia de Julio César, los discursos más memorables, son, asimismo, los más cortos. Recordemos: "Et tu, Brute? Then fall, Caesar" (Sweeney, 2000, p. 92) la frase latina insertada en una obra escrita en inglés moderno temprano. ${ }^{14}$

El profesor Robert Miola, en sus textos Shakespeare's Ancient. Rome: difference and identity (2002) y Julius Caesar: Rome divided (2004) nos refiere que la romanización en Shakespeare se ficcionaliza y teatraliza revelando una imagen diferente y distinta de aquella cuidad que encarnaba normas, valores y virtudes romanitas. Sobre el escenario, Roma es oscura, brutal, feroz, sanguinaria, bárbara y cruenta. E1 asesinato de Julio César o el suicidio de Cleopatra o la venganza de Tito Andrónico son sangrientamente escenificados en momentos visualmente memorables que sobrevivirán a la historia y la literatura pues la ilusión dramática los mantiene vivos.

Por otro lado, durante el renacimiento isabelino, la antigua Roma fue ampliamente exaltada por el encanto de la elocuencia y la oratoria. Miola sostiene que el dramaturgo supo amalgamar aquella violencia (diferencia) con la belleza (identidad) de la antigüedad clásica. El teatro renacentista, como escenario discursivo de la época, también se convierte en un espacio para representar a Roma frente a una audiencia culturalmente heterogénea. Este drama histórico romano es un campo de duelo en

13. A diferencia de Macbeth que también pone en escena las consecuencias y castigo en torno a la muerte de Rey Duncan, la obra lleva el nombre del asesino.

14. A propósito de ello, Barbara Gaines, directora del Chicago Shakespeare Theater, asegura que es muy difícil convencer a un renombrado actor para protagonizar el papel de César; pues, aunque su espíritu, liberado de su cuerpo mortal impregna toda la obra, solo articula 16 palabras en la segunda parte del drama (Wills, 2011, p. 1). 
el que una gran variedad de discursos opuestos (Bruto y Marco Antonio) convergen sobre el cadáver de Julio César; es una batalla verbal que abarca desde la explicación, exculpación y justificación hasta la persuasión, seducción e incitación. Sin duda, las destrezas aprendidas en el estudio de la retórica clásica y su inigualable capacidad para sondear las profundidades de la crueldad humana nos permiten comprender, entonces, por qué el crítico literario Harold Bloom (2016, p. 45) ubica las obras de William Shakespeare en el centro los textos preceptivos que conforman el canon occidental de la literatura.

\section{Referencias bibliográficas}

Ackroyd, P. (2005). Shakespeare. The Biography. London, Doubleday.

Asimov, I. (1966). The Roman Republic. UK, Houghton Mifflin Harcourt.

Bloom, H. (2008). Las tragedias del aprendizaje. En La invención de lo humano (pp. 146-164). Bogotá, Norma.

Bloom, H. (2016). El canon occidental. Barcelona, Anagrama.

Cantor, P. (2017). Shakespeare's Rome: Republic and Empire. USA, The University of Chicago Press.

Chernaik, W. (2011). Like a Colossius: Julius Caesar. En The Myth of Rome in Shakespeare and his Contemporaries (pp. 89-110). UK, CUP.

Chesterton, G. K. (2013). Pequeña historia de Inglaterra. Madrid, Losada.

Churchill, W. (1958). Historia de Inglaterra y de los pueblos de habla inglesa. Tomo I. Nace Gran Bretaña. Buenos Aires, Peuser.

Corbet, E. y Connors, R. J. (1999). Classical rhetoric for the Modern Student. Oxford, OUP.

Earley, M. (1988). Soliloquy! The Shakespeare's Monologues (Men). USA, Applause Thearte \& Cinema Books.

Grazia, M. de (2001). What did Shakespeare read? En Cambridge Companion to William Shakespeare (pp. 31-48). UK, CUP.

Griffin, M. (2009). Shakespeare's Julius Caesar and the Dramatic Tradition. En A Companion to Julius Caesar (pp. 371-398). UK, Blackwell Publishing Ltd.

Hutchins, R. M. (1952). Plutarch. The Lives of the Noble Grecians and Romanes (14 vols., Th. North, trad.). UK, Encyclopaedia Britannica.

Miola, R. (2002). Shakespeare's Ancient Rome: difference and identity. En Hattaway, M. (ed.), The Cambridge Companion to Shakespeare's History Plays (pp. 193-213). Cambridge, Cambridge University Press.

Miola, R. (2004). Shakespearés Rome. UK, CUP. 
Palfrey, S. (2011). Provate and Public Rethoric: Brutus in Julius Caesar. En Doing Shakespeare (pp. 253-278). UK, Bloomsbury Publising.

Shakespeare, W. (2012). Julio César. España, Edu Robsy.

Shapiro, J. (2005). A Year in the Life of William Shakespeare: 1599. UK, Harper Collins Publishers.

Sweeney, D. (2000). Shakespearés Julius Caesar. NY, Hungry Minds.

Tomlin, R. (2018). Britannia Romana. UK, Oxford Books.

Townson, D. (2015). Breve Historia de Inglaterra. España, Alianza.

Wills, G. (2011). Rome and Rethoric: Shakespearés Julius Caesar. USA, Yale University Press.

*María Angelina Cazorla es Profesora de Inglés, Licenciada en Lenguas Extranjeras y Licenciada en Letras. Profesora Adjunta concursada de las cátedras Literatura de Europa Septentrional del Departamento de Letras de la Facultad de Humanidades e Inglés I de la Facultad de Arte, Diseño y Ciencias de la Cultura (FADyCC), ambas instituciones pertenecientes a la Universidad Nacional del Nordeste (UNNE).

RECIBIDO: 01/02/2021

ACEPTADO: 28/05/2021 